PENGARUH PERSEPSI ETIKA BISNIS ISLAM, PERSEPSI KUALITAS PRODUK DAN PERSEPSI KUALITAS PELAYANAN TERHADAP TINGKAT PENJUALAN UMKM KOTA YOGYAKARTA

Intan Resti Riana*

Universitas Ahmad Dahlan

Email: intanrr24@gmail.com

\title{
Lu'lu' Nafiati
}

Universitas Ahmad Dahlan

Email: lulu.nafiati@gmail.com

* Corresponding Author

\begin{abstract}
Many SMEs players who do not apply Islamic business ethics, showing the importance of research on Islamic business ethics. This study aims to examine the factors that affect the level of sales of Small and Medium Enterprises (SMEs) in Yogyakarta city. Determination of the sales level tested in this study is the perception of Islamic business ethics, service quality and product quality. This research uses a survey method involving SMEs owner. The sample selection method used was accidental sampling. The results were tested by using multiple linear regression tests. The results showed that Islamic business ethics, service quality and product quality had a positive effect on the sales level of SMEs in Yogyakarta city.
\end{abstract}

Keywods: Islamic Business Ethics, Service Quality, Product Quality, Sales.

\section{PENDAHULUAN}

Usaha Mikro Kecil dan Menengah berperan penting dalam mengatasi persoalan kemiskinan di Daerah Istimewa Yogyakarta. Salah satu kebijakan strategis Pemerintah DIY dalam mengatasi kemiskinan melalui ekonomi rakyat ialah dengan mengadakan pembinaan dan pemberdayaan UMKM. Provinsi DIY tercatat masih memiliki angka kemiskinan yang tinggi, yaitu mencapai 11,81 persen diatas rata-rata angka nasional yang hanya 9,66 persen. Hal tersebut menjadi alasan yang tepat untuk menjadikan UMKM sebagai penguat ekonomi rakyat DIY.

UMKM diharapkan mampu bergerak dalam mengurangi angka kemiskinan di DIY. Oleh karena itu, penting untuk mengetahui faktor-faktor yang mendorong keberhasilan UMKM yang diukur dengan tingkat penjualan. Penelitian ini berfokus pada variabel etika bisnis islam, kualitas produk dan kualitas pelayanan.

Masih banyak pelaku UMKM yang tidak mencerminkan penerapan etika bisnis Islam. Terbukti dari masih ditemukan sebagian UMKM yang menggunakan bahan kimia berbahaya dan produksi tanpa memperhatikan kebersihan makananan. Pada pusat data 
Intan Resti Riana, Lu’lu’ Nafiati | Pengaruh Persepsi Etika Bisnis Islam, Persepsi Kualitas Produk ...

dan informasi Kementerian Kesehatan RI 2015 dijelaskan bahwa masih terdapat banyak pangan tidak sehat yang beredar. Pengujian Pangan Jajanan Anak Sekolah (PJAS) yang dilakukan Kemenkes pada tahun 2013 membuktikan bahwa ada 4 dari 7 sampel jajanan yang diuji tidak memenuhi syarat pangan sehat karena mengandung bahan berbahaya yang dilarang, empat makanan tersebut adalah produk minuman es, sirup, bakso dan jelly. Kemenkes juga mengatakan penyakit yang disebabkan oleh makanan tidak sehat dan diare membunuh sekitar 2 juta orang pertahun, termasuk juga anak-anak (Infodatin Kemenkes, 2015). Pada bulan Mei 2019 BPOM DIY menemukan sejumlah makanan yang positif mengandung bahan kimia berbahaya saat melakukan sidak di Pasar Jangkang, Ngemplak, Sleman. Bahan kimia berbahaya yang ditemukan pada teri nasi dan cumi kering yaitu formalin, ada juga mie kuning yang mengandung boraks dan kerupuk dengan bahan pewarna berbahaya, Rodhamin B (Ermando, 2019).

Perilaku tersebut merupakan sebuah kejahatan yang melanggar etika dan tentu bertentangan dengan nilai-nilai Islam. Dunia bisnis tidak selalu tentang profit. Dunia bisnis juga berfungsi sebagai sarana sosial dan harus menerapkan etika yang berlaku di masyarakat. Para pelaku usaha juga harus menghindari berbagai hal yang akan merugikan orang lain hanya demi mengejar keuntungan diri sendiri (Anindya, 2017). Penelitian terdahulu yang dilakukan oleh Athfal (2016), Ayyubi \& Anggraini (2017), Nisa (2019), Saputra (2016) menunjukkan bahwa terdapat pengaruh antara etika bisnis Islam terhadap tingkat keuntungan usaha, kinerja finansial dan tingkat penjualan.

Kualitas pelayanan juga merupakan salah satu faktor yang memengaruhi tingkat penjualan. Menurut Lovelock (2010), kualitas pelayanan adalah sesuatu yang secara konsisten dapat memenuhi dan melampaui harapan para konsumen. Pelayanan yang berkualitas akan menjadi daya tarik bagi konsumen dan akan berdampak juga pada terjadinya pembelian berulang-ulang yang nantinya akan meningkatkan penjualan. Penelitian terdahulu yang dilakukan oleh Apriansyah (2018), Bahari \& Tissaeni (2016), Lestari dkk., (2017), Nugraha dkk., (2016), Sasangka (2018), Sumawardani dkk., (2016), Susetiyo dkk., (2016) menunjukkan hasil bahwa kualitas pelayanan berpengaruh positif terhadap tingkat penjualan.

Selain kualitas pelayanan, yang harus diperhatikan perusahaan dalam meningkatkan penjualan adalah kualitas produk. Kualitas produk adalah kemampuan suatu produk untuk melaksanakan fungsinya yaitu meliputi daya tahan, keandalan, ketepatan, kemudahan operasi dan perbaikan serta atribut lainnya (Kotler dan amstrong, 2008). Untuk mencapai sebuah kualitas yang baik diperlukan sebuah standar kualitas, yang dimaksudkan untuk menjaga produk agar selalu memenuhi standar sehingga tidak mengurangi ataupun menghilangkan rasa kepercayaan konsumen terhadap produk yang kita miliki. Perusahaan yang tidak memperhatikan kualitas produk akan berakibat kepada ketidakloyalan konsumen, dan cenderung penjualannya pun ikut turun. Penelitian terdahulu yang dilakukan oleh Kil'it (2016), Nasution dkk., (2017), Manik (2015), Mokalu \& Tumbel (2015), Susetiyo dkk., (2016), Widyaningrum (2009) mendapatkan hasil penelitian yaitu kualitas produk berpengaruh positif terhadap tingkat penjualan. 
Intan Resti Riana, Lu’lu’ Nafiati | Pengaruh Persepsi Etika Bisnis Islam, Persepsi Kualitas Produk ...

Objek yang akan digunakan pada penelitian ini adalah UMKM yang ada di Kota Yogyakarta, karena berdasarkan data yg dirilis oleh Dinas Koperasi dan UKM DIY, 95\% perekonomian DIY ditopang oleh UMKM (Handito, 2016). Selain itu, UMKM di DIY juga terus berkembang dimana setiap tahunnya mengalami pertumbuhan dua persen. UMKM yang memiliki potensi paling besar di DIY adalah UMKM bidang kuliner dan fashion (Ismiyanto, 2019).

Penelitian ini berkontribusi terhadap literatur etika bisnis Islam dalam kaitannya terhadap tingkat penjualan. Masih sedikit penelitian yang menguji variabel ini pada tingkat UMKM yang berada pada industri kuliner. Penelitian ini juga memiliki kontribusi praktis khususnya kepada para pembuat kebijakan terkait UMKM, untuk mampu mendorong pemahaman akan pentingnya etika bisnis Islam dalam menjalankan UMKM. Etika bisnis Islam mampu menjaga sustainabilitas usaha secara jangka panjang, karena adanya kepercayaan terhadap penjual dari pembeli.

\section{METODE PENELITIAN}

Penelitian ini menggunakan metode survei dan mengambil lokasi di Kota Yogyakarta. Lokasi ini dipilih secara sengaja dengan pertimbangan Kota Yogyakarta memiliki banyak UMKM dan masih sering terjadi pelanggaran-pelanggaran yang dilakukan oleh pelaku UMKM (Ermando, 2019). Pengujian dilakukan dengan menggunakan sampel yang terdiri dari 54 responden.

Pengukuran terhadap variabel etika bisnis Islam mengacu pada indikator dari AlQur'an dan Hadits yang sudah dikembangkan oleh Ayyubi \& Anggraini (2017). Kualitas produk diukur dengan menggunakan instrumen dari Tjiptono \& Chandra (2005). Pengukuran variabel kualitas pelayanan mengacu pada indikator dari Zeithaml dkk. (2000) yang telah diterjemahkan dalam konteks Indonesia oleh Apriansyah (2018). Tingkat penjualan diukur dengan menggunakan indikator dari Philip Kotler yang dikutip oleh Swastha dan Irawan (2008) yang meliputi mencapai volume penjualan, mendapatkan laba dan menunjang pertumbuhan perusahaan. Kuesioner diukur menggunakan skala likert 5 poin dengan rentang Sangat Setuju hingga Sangat Tidak Setuju.

\section{HASIL DAN PEMBAHASAN}

\section{Deskripsi Responden}

Deskriptif jenis usaha responden bertujuan mengetahui mayoritas responden memiliki fokus bidang usaha responden. Berikut ini merupakan data responden jika dilihat berdasarkan jenis usaha. 
Intan Resti Riana, Lu’lu’ Nafiati | Pengaruh Persepsi Etika Bisnis Islam, Persepsi Kualitas Produk ...

Tabel 1. Jenis Usaha Responden

\begin{tabular}{lrr}
\hline Jenis Usaha & Frekuensi & Persentase \\
\hline Industri Pengolahan & 2 & 3,7 \\
Restoran/Rumah Makan & 13 & 24,1 \\
Café & 3 & 5,6 \\
Outlet Kue dan Roti & 4 & 7,4 \\
Outlet Makanan Ringan & 14 & 25,9 \\
Outlet Minuman & 8 & 14,8 \\
Outlet Oleh-oleh & 2 & 3,7 \\
Lainnya & 8 & 14,8 \\
\hline
\end{tabular}

Berdasarkan tabel 1. dapat dilihat bahwa sebagian besar UMKM berjenis usaha restoran/rumah makan dan outlet makanan ringan.

\section{Uji Kualitas Data}

\subsection{Uji Validitas}

Uji validitas digunakan untuk mengukur valid atau tidaknya suatu kuesioner. Uji validitas dalam penelitian ini dilakukan dengan membandingkan nilai $r$ hitung dengan nilai $r$ tabel untuk degree of freedom $(\mathrm{df})=\mathrm{n}-2$, dalam hal ini $\mathrm{n}$ adalah jumlah sampel yaitu $(\mathrm{df})=54-2$ sebesar 0,2262. Berdasarkan uji validitas yang dilakukan, hasil menunjukkan valid untuk 11 item pertanyaan yang dipakai variabel etika bisnis islam, 13 item pertanyaan yang dipakai variabel kualitas produk, 20 item pertanyaan yang dipakai variabel kualitas pelayanan, dan 6 item pertanyaan yang dipakai variable tingkat penjualan.

\subsection{Uji Reliabilitas}

Suatu kuesioner dikatakan reliabel jika jawaban responden terhadap pertanyaan adalah konsisten atau stabil dari waktu ke waktu. Untuk mengukur reliabilitas maka digunakan uji statistik Cronbach Alpha $(\alpha)$ pada SPSS. Suatu variabel dikatakan reliabel jika memberikan nilai Cronbach Alpha > 0,60 (Ghozali, 2018). Hasil pengujian menunjukkan bahwa nilai Cronbach Alpha untuk semua variabel yang terdiri dari persepsi etika bisnis Islam, kualitas produk, kualitas pelayanan dan tingkat penjualan menunjukan angka $>0,60$ yang berarti semua item reliabel.

\subsection{Uji Asumsi Klasik}

Uji Asumsi Klasik dalam penelitian ini dilakukan sebagai syarat sebelum dilakukan Uji Regresi Berganda, sehingga hasil penelitian terhindar dari hasil yang bias. Uji asumsi klasik pada penelitian ini dilakukan dengan menggunakan uji normalitas, uji multikoleniaritas, uji heterosteskedasitas. Uji normalitas menunjukkan bahwa nilai Asymp.sig (2-tailed) 0,200 >0,05. Maka dapat diambil kesimpulan bahwa data residual 
Intan Resti Riana, Lu’lu’ Nafiati | Pengaruh Persepsi Etika Bisnis Islam, Persepsi Kualitas Produk ...

pada penelitian ini berdistribusi normal. Uji multikoleniaritas menunjukkan hasil pengujian bahwa nilai tolerance semua variabel $>0,10$ dan nilai VIF semua variabel $<10$. Maka dapat disimpulkan bahwa tidak terjadi multikolinearitas antar variabel independen. Uji heteroskedastisitas menunjukan bahwa nilai signifikansi > nilai alpha, maka dapat disimpulkan bahwa seluruh variabel dalam penelitian ini tidak terjadi heteroskedastisitas.

\subsection{Uji Regresi}

Regresi berganda digunakan untuk menganalisis hubungan dan pengaruh dari beberapa variabel. Variabel independen dalam penlitian ini adalah etika bisnis Islam, kualitas produk dan kualitas pelayanan sedangkan variabel dependennya adalah tingkat penjualan. Berikut adalah analisis regresi berganda dengan menggunakan software SPSS:

Table 2. Hasil Uji Regresi Berganda

\begin{tabular}{llcccl}
\hline \multicolumn{1}{c}{ Variabel } & \multicolumn{2}{c}{ Signifikansi } & \multirow{2}{*}{ Koefisien } & Alpha & \multirow{2}{*}{ Keputusan } \\
& Two-tail & One-tail & & & \\
\hline Etika Bisnis Islam & 0,852 & 0,426 & 0,012 & 0,05 & $\mathrm{H}_{1}$ tidak terdukung \\
Kualitas Produk & 0,009 & 0,0045 & 0,226 & 0,05 & $\mathrm{H}_{2}$ terdukung \\
Kualitas Pelayanan & 0,024 & 0,012 & 0,164 & 0,05 & $\mathrm{H}_{3}$ terdukung \\
\hline Konstanta & $=3,546$ & & & & \\
Adjusted R square & $=0,521$ & & & & \\
F statistik & $=20,244$ & & & & \\
Signifikansi & $=0,000$ & & & & \\
\hline
\end{tabular}

Sumber: Data Primer, Diolah (2020)

Berdasarkan hasil pengujian tabel 4.17 dapat dirumuskan suatu persamaan regresi untuk mengetahui pengaruh variabel independen terhadap variabel dependen sebagai berikut :

$$
\begin{aligned}
& Y=3,546+0,226 X_{2}+0,164 X_{3}+e \\
& Y=\text { Tingkat Penjualan } \\
& \alpha=\text { Konstanta } \\
& X_{2}=\text { Kualitas Produk } \\
& X_{3}=\text { Kualitas Pelayanan } \\
& e \quad=\text { Standart error }
\end{aligned}
$$

Koefisien-koefisien persamaan regresi linear berganda diatas dapat diartikan sebagai berikut:

a. Nilai konstanta sebesar 3,546 mengindikasikan tanpa adanya pengaruh variabel independen yang digunakan pada penelitian ini, maka nilai tingkat penjualan sebesar 3,546. 
Intan Resti Riana, Lu’lu’ Nafiati | Pengaruh Persepsi Etika Bisnis Islam, Persepsi Kualitas Produk ...

b. Koefisien regresi pengaruh kualitas produk $\left(X_{2}\right)$ sebesar 0,226 yang berarti bahwa setiap variabel kualitas produk naik satu satuan akan meningkatkan tingkat penjualan UMKM sebesar 0,226 dengan asumsi variabel lain konstan.

c. Koefisien regresi pengaruh kualitas pelayanan $\left(X_{3}\right)$ sebesar 0,164 yang berarti bahwa setiap variabel kualitas pelayanan naik satu satuan akan meningkatkan tingkat penjualan UMKM sebesar 0,164 dengan asumsi variabel lain konstan.

Berdasarkan Tabel 3.2, Adjusted R-square (Koefisien Determinasi) bernilai 0,521 yang berarti 52,1\% tingkat penjualan UMKM dipengaruhi oleh variabel independen. Sedangkan sisanya 47,9\% dijelaskan oleh variable lain. Hasil dari perhitungan F didapatkan nilai sig $0,000<0,05$ yang berarti bahwa etika bisnis Islam, kualitas produk dan kualitas pelayanan secara simultan berpengaruh terhadap tingkat penjualan UMKM.

Berdasarkan hasil pengujian regresi berganda menunjukkan bahwa $\mathrm{H}_{1}$ tidak terdukung, yang artinya variabel etika bisnis Islam tidak berpengaruh terhadap tingkat penjualan. Prinsip etika bisnis Islam para pelaku UMKM di Kota Yogyakarta belum sepenuhnya diterapkan dengan baik. Dilihat dari hasil kuesioner kebanyakan responden memilih tidak setuju ataupun ragu-ragu pada poin bersaing secara sehat dengan usaha sejenis, menjelaskan kelemahan dan kelebihan produk serta membayar zakat ketika sudah mencapai nisab. Pernyataan ini didukung oleh penelitian yang dilakukan oleh Hasanah (2017) yang menyatakan bahwa etika bisnis Islam tidak berpengaruh terhadap tingkat penjualan UMKM.

Berdasarkan hasil pengujian regresi berganda menunjukkan bahwa $\mathrm{H}_{2}$ terdukung, yang artinya variabel kualitas produk berpengaruh positif terhadap tingkat penjualan. Hal ini menunjukkan bahwa kualitas produk yang dijual oleh para pelaku UMKM di Kota Yogyakarta mutu dan kualitasnya sudah cukup baik. Jika kualitas produk baik dan selalu ditingkatkan, konsumen akan merasa puas dan percaya dengan produk yang dijual. Sehingga konsumen akan terus berlangganan dan tidak menutup kemungkinan konsumen akan menyebarluaskan informasi tersebut lalu membuat jumlah konsumen kita bertambah dan akan meningkatkan penjualan UMKM. Hal ini didukung oleh penelitian yang dilakukan Kil'it (2016), Manik (2015), Mokalu \& Tumbel (2015), Nasution dkk.,(2017), Susetiyo dkk., (2016), dan Widyaningrum (2009) yang menyatakan bahwa kualitas produk berpengaruh terhadap tingkat penjualan UMKM di Kota Yogyakarta.

Berdasarkan hasil pengujian regresi berganda menunjukkan bahwa $\mathrm{H}_{3}$ terdukung, yang artinya variabel kualitas pelayanan berpengaruh positif terhadap tingkat penjualan. Hal ini menunjukkan bahwa kualitas pelayanan yang diterapkan oleh para pelaku UMKM di Kota Yogyakarta kualitasnya sudah cukup baik. Jika kualitas pelayanan yang diberikan UMKM sesuai dengan harapan dan keinginan para konsumen maka konsumen akan tertarik dan mau membeli produk yang dijual oleh UMKM, hal ini lah yang mendorong peningkatan penjualan. Pernyataan ini didukung oleh penelitian yang dilakukan Apriansyah (2018), Bahari dan Tissaeni (2016), Lestari dkk., (2017), Nugraha dkk., (2016), Sasangka (2018), Sumawardani dkk., (2016) dan Susetiyo dkk., (2016) yang menyatakan bahwa kualitas pelayanan berpengaruh terhadap tingkat penjualan UMKM di Kota Yogyakarta. 
Intan Resti Riana, Lu’lu’ Nafiati | Pengaruh Persepsi Etika Bisnis Islam, Persepsi Kualitas Produk ...

\section{KESIMPULAN}

Berdasarkan hasil penelitian dan pembahasan, maka dapat diambil kesimpulan bahwa persepsi etika bisnis Islam tidak berpengaruh terhadap tingkat penjualan UMKM di Kota Yogyakarta, persepsi kualitas produk dan persepsi kualitas pelayanan berpengaruh positif terhadap tingkat penjualan UMKM di Kota Yogyakarta. Prinsip etika bisnis Islam para pelaku UMKM di Kota Yogyakarta belum sepenuhnya diterapkan dengan baik. Dilihat dari hasil kuesioner kebanyakan responden memilih tidak setuju ataupun ragu-ragu pada poin bersaing secara sehat dengan usaha sejenis, menjelaskan kelemahan dan kelebihan produk serta membayar zakat ketika sudah mencapai nisab.

Penelitian ini memiliki keterbatasan jumlah responden. Sampel yang digunakan dalam penelitian ini terbatas dibandingkan dengan UMKM yang ada di Kota Yogyakarta. Hal ini dikarenakan adanya pandemi COVID-19 pada tahun 2020 yang mengharuskan masyarakat untuk meminimalisir aktivitas di luar rumah.

Penelitian berikutnya diharapkan menambahkan variabel independen lain seperti variabel harga, citra merek, promosi, desain dan lain-lain agar hasil penelitian yang didapat lebih signifikan. Penelitian selanjutnya sebaiknya juga melalukan pengambilan data dengan metode wawancara atau kuesioner yang disebar secara langsung agar hasil penelitiannya dapat menggambarkan kondisi yang sebenarnya dari para pelaku UMKM. Selain itu, penelitian selanjutnya diharapkan agar menambah jumlah sampel dengan cara mengambil objek penelitian yang lain supaya hasil penelitian lebih signifikan.

\section{REFERENCES}

Anindya, D. (2017). Pengaruh Etika Bisnis Islam Terhadap Keuntungan Usaha Pada Wirausaha di Desa Delitua Kecamatan Delitua. At-Tawassuth, II(2), 389-412

Apriansyah, R. (2018). Pengaruh Kualitas Pelayanan Dan Promosi Terhadap Volume Penjualan Pada Pt. Prioritas Rengat. Jurnal Manajemen Dan Bisnis, 7(2), 37-45. https://doi.org/10.34006/jmbi.v7i2.48

Athfal, A. M. (2016). Strategi Marketing Dalam Meningkatkan Volume Penjualan Perspektif Etika Bisnis Islam (Studi Kasus pada PT . Lestari Jaya Kebasen Banyumas).

Ayyubi, S. El, \& Anggraini, S. A. (2017). Peran etika bisnis Islam terhadap kinerja usaha mikro, kecil, dan menengah (UMKM) pangan di Kota Bogor.

Journal of Business and Banking, 6, 183-194. https://doi.org/10.14414/jbb.v6i2.1299

Bahari, C., \& Tissaeni, E. (2016). Pengaruh Kualitas Pelayanan dan Harga Terhadap Penjualan Ikan Air Tawar PD. Sarakan Domas Subang Jawa Barat. GEMA Ekonomi, 05(02), 107-113.

Ermando, A. (2019). Sidak di Pasar Jangkang BPOM DIY Kembali Temukan Makanan Mengandung Formalin dan Boraks. https://jogja.tribunnews.com/2019/05/29/ sidak-di-pasar-jangkang-bpom-diy-

kembali-temukan-makanan-mengandung-formalin-dan-boraks. Diakses tanggal 27 September 2019. 
Intan Resti Riana, Lu’lu’ Nafiati | Pengaruh Persepsi Etika Bisnis Islam, Persepsi Kualitas Produk ...

Handito, D. N. (2016). LIPSUS : 95 Persen Perekonomian DIY Disumbang oleh

UMKM. https://jogja.tribunnews.com/2016/06/22/lipsus-95-persen-perekonomian-diydisumbang-oleh-umkm. Diakses 21 September 2020.

Ismiyanto, Agung.(2019). UKM DIY Tumbuh 2 persen Per Tahun

https://jogja.tribunnews.com/2019/10/11/ukm-diy-tumbuh-2-persen-per-tahun. Diakses 21 September 2020.

Kil'it, D. (2016). Pengaruh Kualitas Produk dan Harga Terhadap Volume Penjualan Pada Distro Popin Pangkal Pinang. 1-17.

Lestari, Y., Rusman, T., \& Nurdin. (2017). Pengaruh Kualitas Pelayanan, Promosi Penjualan dan Kepuasan Konsumen terhadap Volume Penjualan. (01).

Manik, C. D. (2015). Pengaruh Kualitas Produk, Harga, Dan Promosi Terhadap Tingkat Penjualan (Studi Kasus Pada Perumahan Serpong Garden). Jurnal Ilmiah, 3(1), 40-51.

Mokalu, F. O., \& Tumbel, A. (2015). Pengaruh Kualitas Produk, Harga dan Distribusi Terhadap Volume Penjualan Roti Jordan CV. Minahasa Mantap Perkasa. Jurnal EMBA, 3(1), 254-265.

Nasution, M. I., Prayogi, M. A., \& Nasution, S. M. A. (2017). Pengaruh Kualitas Produk, Promosi Terhadap Penjualan pada Usaha Mikro Pengrajin Sepatu di Kecamatan Medan Denai. Prosiding, 7(1), 60-70.

Nisa, H. K. (2019). Pengaruh Etika Bisnis Islam Pedagang Pakaian Terhadap Tingkat Penjualan di Pasar Legi Citra Niaga Jombang.

Nugraha, M. A., Yulianthini, N. N., \& Susila, gede putu agus jana. (2016). Pengaruh Harga, Kualitas Pelayanan, Promosi Terhadap Penjualan. E-Journal Bisma Universitas Pendidikan Ganesha, 4(1).

Saputra, F. Y. (2016). Pengaruh Penerapan Etika Bisnis Islam Terhadap Keuntungan Usaha Pengusaha Laundry di Kecamatan Tembalang.

Sasangka, I. (2018). Pengaruh Kualitas Pelayanan Terhadap Volume Penjualan Pada Mini Market Minamart"90 Bandung. Jurnal Ilmiah Manajamen Ekonomi Dan Akuntansi, 2(1).

Sumawardani, Minarsih, P. M., \& Warso, M. M. (2016). Pengaruh Kualitas Pelayanan, Desain, Dan Harga Terhadap Kepuasan Pelanggan Yang Berdampak Pada Peningkatan Penjualan Di Percetakan Teaching Factory Gradasi Semarang. Journal of Management, 2(2).

Susetiyo, B. A., Afifuddin, S., \& Ayu, S. F. (2016). Pengaruh kualitas produk, kualitas pelayanan dan kepuasan pelanggan terhadap penjualan karet di pt. perkebunan nusantara iii (persero). Agrica (Jurnal Agribisnis Sumatera Utara), 4(1), 20-28.

Widyaningrum, I. Y. R. (2009). Pengaruh Kualitas Produk Terhadap Volume Penjualan Pada Home Industri Kripik Tempe “Abadi” Singgahan Kecamatan Kartoharjo. 1-10. 